\title{
O Uso da Ferramenta Cognitiva Fórum no Processo de Ensino- Aprendizagem na Modalidade a Distância
}

Title: The Use of a Cognitive Tool Forum in the Teaching-Learning Process in the Modality of the Distance

\section{Danielli Veiga Carneiro Sondermann}

Centro de Referência em Formação e em Educação a Distância (Cefor) - Instituto Federal do Espírito Santo - Serra, ES - Brasil

danielli@ifes.edu.br

\author{
Yvina Pavan Baldo \\ Centro de Referência em Formação e em Educação a Dis- \\ tância (Cefor) - Instituto Federal do Espírito Santo - Serra, \\ ES - Brasil \\ yvina@ifes.edu.br
}

Resumo Este artigo de cunho qualitativo, apresenta um recorte de uma pesquisa-ação na área de Design Educacional Inclusivo sobre as configurações da ferramenta cognitiva Fórum e os impactos causados na interação do aluno-aluno, aluno-tutor e aluno-professor. A pesquisa foi realizada em um curso de formação para Educação a Distância em uma instituição pública de ensino. A pesquisa-ação foi organizada com três grupos focais: Grupo 1 - equipe de produção, Grupo 2 Professores; Grupo 3 - Alunos, dentre os alunos um com deficiência visual e três surdos. Os resultados reforçam a importância da forma de mediação como fator de sucesso para a construção do conhecimento.

Palavras-Chave: Educação a Distância, Design Educacional, Fórum, Pesquisa-ação.

\begin{abstract}
This article qualitative, shows a cutout of an action research in the area of Educational Design Inclusive on the settings of cognitive tool Forum and the impacts caused the interaction of student-student, student-tutor and student-teacher. The research was conducted in a training course for Distance Education at a public institution of education. The action research was organized with three focus groups: Group 1 - production team, Group 2 - Teachers; Group 3 Students, among students with visual disabilities and three deaf. The results reinforce the importance of the form of mediation as a factor of success for the construction of knowledge.
\end{abstract}

Keywords: Distance Education, Educational Design, Forum, Action research. 


\section{Introdução}

O crescimento da Educação a Distância (EaD) no Brasil tem impulsionado uso das Tecnologias de Informação e Comunicação (TICs) nas práticas educacionais, independente da modalidade de ensino. Entretanto, ainda tem-se muitos desafios para se utilizar as ferramentas disponíveis de maneira efetiva para que a aprendizagem realmente aconteça de maneira colaborativa e reflexiva.

A Educação a Distância tem proporcionado ações em prol do aumento no número de matrículas em regiões distantes das instituições presenciais de ensino e também ações em torno da Educação Inclusiva, sobretudo, em questões de deficiência física com dificuldade de deslocamento, e, ainda, naquelas deficiências que necessitam de material acessível, por exemplo, a deficiência visual e a surdez.

Uma das ferramentas cognitivas muito utilizadas na EaD é o Fórum, uma ferramenta assíncrona de uso 'simples' para comunicação textual, mas em alguns momentos, o número excessivo de mensagens para quem não realiza o acompanhamento diário, pode tornar-se algo 'complexo'. Por meio das possíveis interações entre alunoaluno, aluno-tutor e aluno-professor é possível a construção do conhecimento, por meio de troca de ideias, sugestões, elogios e impressões, a qualquer momento de um curso, salvo nos casos, em que os tempos são demarcados previamente por meio de um calendário acadêmico específico.

Este artigo tem como objetivo apresentar um recorte de uma pesquisa-ação na área de Design Educacional Inclusivo sobre o planejamento, a construção, o uso e a avaliação de um Fórum em uma disciplina na modalidade a distância em um curso de formação de professores em uma instituição pública de ensino.

\section{O planejamento de disciplinas e o uso do Fórum da modalidade a dis- tância}

Os cursos na modalidade a distância, normalmente, são planejados por meio de alguma matriz ou mapa de atividades que detalha todos os conteúdos, os objetivos, as atividades, os recursos do Ambiente Virtual de Aprendizagem (AVA) utilizados e a forma de avaliação.

A Figura 1 apresenta um modelo de Mapa de Atividades adotado pelo Centro de Referência em Formação e em Educação a Distância (Cefor) do Instituto Federal do Espírito Santo (Ifes), este foi elaborado a partir de outros já existentes e que vem sofrendo alterações ao longo dos últimos anos, tendo o objetivo de orientar o professor na organização de objetivos, de conteúdos e de atividades propostas em disciplinas na modalidade a distância. Outros itens surgiram da necessidade em fazer com que o professor em conjunto com o designer instrucional (profissional responsável pelo apoio ao planejamento educacional), identificasse o recurso do Moodle mais apropriado para a atividade proposta, esta poderá ter um cunho mais teórico ou prático. A coluna de grau de dificuldade foi inserido devido à oferta de disciplinas simultâneas, de forma a organizar as disciplinas, sem sobrecarregar o aluno com atividades que exigem maior esforço em uma mesma semana, por exemplo, dois trabalhos em grupo no mesmo período, que exige muitos encontros (síncronos e assíncronos) para a organização do trabalho.

É comum em um curso de EaD avaliar com determinada pontuação as atividades realizadas, respeitando a legislação em vigor de acordo com o nível de ensino, por isso foi inserido a coluna nota, permitindo assim saber se as avaliações presenciais possuem maior peso, por exemplo, para o caso dos cursos de graduação, pois esta é uma exigência legal. O campo '\%' foi inserido após muitas discussões sobre a carga horária destinada a determinados conteúdos, típicos do planejamento do ensino presencial, julgou-se o termo percentual mais adequado para identificar a carga horária da disciplina, devido aos ritmos diferenciados do corpo discente, dificilmente atribuir um valor-hora irá refletir a realidade em termos de planejamento educacional.

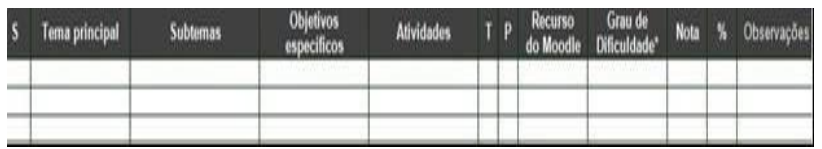

FIGURA 1. Modelo de Mapa de Atividades

Fonte: Cefor/Ifes.

Observando a Figura 1 da esquerda para a direita, apresentamos a seguir uma descrição de cada um dos itens que compõem o Mapa de Atividades apresentado:

\section{$1-\mathrm{S}$ (semanas)}

Os cursos oferecidos na modalidade a distância podem ser distribuídos por aulas, semanas, módulos etc. A orientação é não disponibilizar temas com períodos muito extensos para evitar o acúmulo de atividades. Assim, aulas diárias e/ou semanais compostas por atividades e tarefas mais simples podem disciplinar os acessos ao ambiente virtual de aprendizagem e tornar, naturalmente, a presença e a participação dos alunos mais efetiva.

\section{2 - Tema Principal}

As unidades e/ou temas principais das disciplinas/cursos são os conteúdos que serão aplicados. Nos cursos que oferecem o material impresso, o conjunto de temas deverá formar o sumário do mesmo. 


\section{3 - Subtemas}

Os subtemas são, basicamente, tópicos nos quais o tema principal é desmembrado.

\section{4 - Objetivos Específicos}

Esse é um dos campos mais importantes, pois a partir destes é que são organizados o que se deseja que o aluno alcance. De acordo com os objetivos propostos, o designer instrucional irá avaliar e sugerir a melhor forma para representar o conteúdo e o tipo de atividades que deverão ser realizadas.

\section{5 - Atividades}

Esse item está em estreita relação com o anterior. Nesta coluna, escreve-se sobre todas as atividades, avaliativas e não-avaliativas, que serão propostas ao aluno. É importante diversificar as atividades, criar atividades que envolvam leitura, discussões em Fórum, realização de questionários, trabalhos em grupo, experimento em laboratório, etc. Nele, pode-se analisar as atividades propostas ao longo da oferta da disciplina/curso, as relações entre essas atividades, as sugestões de atividades que podem melhorar, por exemplo, as relações de cooperação entre os alunos e muitas outras intervenções possíveis.

\section{6 - Colunas T e P}

A coluna $\mathrm{T}$ deverá ser assinalada para as atividades de natureza teóricas, ou seja, que envolvam somente leitura, e a coluna $\mathrm{P}$ deverá ser assinalada para atividades que tenham característica prática (resolução de exercícios, experimentos, trabalhos em grupo, etc.). Essa relação é muito passível de discussão, isso porque uma leitura pode levar a uma prática na medida em que ela a possíveis ações de cunho mais prático, mas essa classificação ajuda na melhor organização do que os alunos farão.

\section{7 - Recurso do Moodle}

Nesta coluna deve ser informado o recurso do ambiente virtual de aprendizagem que será utilizado para realizar a atividade proposta. É neste item que encontra-se parte da dificuldade docente no planejamento da EaD.

\section{8 - Grau de Dificuldade}

O grau de dificuldade foi dividido em baixo, médio e alto de acordo com o esforço e tempo exigido para realização da atividade. Esta coluna dará subsídio ao designer instrucional, em conjunto com os professores e a equipe pedagógica, para reorganizar as atividades de acordo com o número de disciplinas ofertadas simultaneamente.

\section{9 - Nota}

Nesta coluna será informada a nota referente à atividade. Algumas atividades poderão não ser avaliadas. De acordo com a legislação de EaD, as atividades avaliativas presenciais (provas, seminários, experimentos, etc.) deverão ter um peso maior do que as atividades desenvolvidas no ambiente virtual.

$$
10-\% \text { (Percentual) }
$$

A coluna \% apresenta o quanto do percentual referente à carga horária da disciplina será alcançado com a atividade proposta. Do mesmo modo que a classificação em atividades teóricas ou práticas, esse item é importante para ajustes e organização.

\section{1 - Observações}

Nessa coluna deve-se indicar as orientações específicas. Exemplo: instalação de software, matriz de correção de atividades, recursos necessários, agendamentos de auditório etc.

Ao final do mapa de atividades, são inseridas as referências básicas e complementares, bem como informações sobre os softwares utilizados, quando for necessário.

Para uma melhor visualização e possibilidade de ações interdisciplinares, por toda a equipe que trabalha no planejamento das disciplinas de um mesmo curso, sugerese a criação de uma sala no Ambiente Virtual de Aprendizagem (AVA) para a disponibilização e troca de experiências com relação aos mapas de atividades de todas as disciplinas. Isso possibilitará ao professor o conhecimento dos recursos utilizados e da forma de trabalho dos diversos componentes curriculares planejados ou em planejamento. Esta é uma das mais importantes características do planejamento prévio da $\mathrm{EaD}$ : a possibilidade do professor conhecer os outros planejamentos da equipe e poder ajustar o seu, evitando repetição de objetivos, ou insistindo mais em objetivos pouco explorados em outros componentes.

Após a entrega no mapa de atividades, o designer instrucional analisa o material com o objetivo de criar instruções que favoreçam a aprendizagem do aluno. Aprovado o mapa de atividades, o professor inicia o processo de redação do material impresso, que deve sempre priorizar uma linguagem dialógica, e depois passa pela revisão, tanto do designer instrucional quanto dos revisores de texto. Essa mesma sequência é utilizada para o desenvolvimento das atividades e das mídias propostas.

Os principais recursos do Moodle utilizados no planejamento de disciplinas à distância, são: Fórum, Tarefa, Wiki e Questionário.

Conforme citado, os docentes iniciantes desta modalidade tem dificuldade em indicar qual a ferramenta do AVA mais indicada para determinado conteúdo, daí a importância do acompanhamento de um designer instrucional/educacional junto ao professor durante este planejamento e, também, no acompanhamento durante toda a 
oferta de uma componente curricular e/ou um curso até o momento de sua avaliação. Um conceito para área de Design Instrucional está relacionado "[...] ao processo sistemático e reflexivo de traduzir princípios de aprendizagem e instrução em planos de materiais didáticos, atividades, recursos, informação e avaliação" [1].

Os pressupostos apresentados por Nevado, Carvalho e Menezes [2] potencializam a construção dos mapas de atividades, que muitas vezes, erroneamente, são caracterizados como algo 'engessado' e servem de críticas contra a EaD. Estes autores, propõem por meio de articulação teórico-prática, estratégias interativas e problematizadoras, currículos flexíveis, materiais interativos na Internet e práticas interdisciplinares. Neste contexto, os fóruns são ferramentas cognitivas que auxiliam e muito na interação da $\mathrm{EaD}$.

A função dos fóruns na plataforma Moodle é permitir a comunicação entre professores, tutores e alunos por meio de debates entre os participantes, ou, ainda, fazer a exposição das atividades realizadas. A forma de comunicação é assíncrona, ou seja, as pessoas não precisam estar conectadas simultaneamente para contribuir dando suas opiniões. Os fóruns permitem, ainda, que várias pessoas acompanhem as discussões sobre um determinado tópico. O Quadro 1 apresenta os principais tipos de configuração de um Fórum extraídos de um Ambiente Virtual de Aprendizagem (AVA), no caso o Moodle:

\begin{tabular}{|c|c|}
\hline $\begin{array}{l}\text { Tipo de } \\
\text { Fórum }\end{array}$ & Descrição \\
\hline $\begin{array}{l}\text { Discussão } \\
\text { simples }\end{array}$ & $\begin{array}{l}\text { É um único tópico em uma única página. } \\
\text { Normalmente é usado para organizar dis- } \\
\text { cussões breves com foco em um tema } \\
\text { preciso. }\end{array}$ \\
\hline $\begin{array}{l}\text { Fórum } \\
\text { geral }\end{array}$ & $\begin{array}{l}\text { É um fórum aberto, onde todos os partici- } \\
\text { pantes podem iniciar um novo tópico de } \\
\text { discussão quando quiserem. }\end{array}$ \\
\hline $\begin{array}{l}\text { Cada usu- } \\
\text { ário inicia } \\
\text { apenas UM } \\
\text { NOVO } \\
\text { tópico }\end{array}$ & $\begin{array}{l}\text { Cada participante pode abrir apenas um } \\
\text { novo tópico de discussão, mas todos po- } \\
\text { dem responder livremente as mensagens, } \\
\text { sem limites de quantidades. Este formato é } \\
\text { usado, por exemplo, nas atividades em que } \\
\text { cada participante apresenta um tema a ser } \\
\text { discutido e atua como moderador da dis- } \\
\text { cussão deste tema. }\end{array}$ \\
\hline $\begin{array}{l}\text { Fórum } \\
\text { Perguntas } \\
\text { e Respos- } \\
\text { tas }\end{array}$ & $\begin{array}{l}\text { Neste fórum um estudante pode ler as } \\
\text { mensagens de outros somente após a pu- } \\
\text { blicação de sua mensagem. Depois disto } \\
\text { pode também responder às mensagens do } \\
\text { grupo, isto permite que a primeira mensa- } \\
\text { gem de cada estudante seja original e in- } \\
\text { dependente. }\end{array}$ \\
\hline
\end{tabular}

QUADRO 1 - Tipos de Fórum
Fonte: Moodle [3].

A configuração de um Fórum pode ajudar na interação, mas sabe-se que quem faz a interação é uma 'pessoa' com outra 'pessoa', ou seja, a tecnologia é um meio que facilita esta interação.

Moore [4] desenvolveu o conceito de 'distância transacional', que vai para além da distância geográfica ou temporal, sendo, sobretudo, um conceito pedagógico. É um conceito que descreve o universo de relações professor-aluno quando estes estão separados no espaçotempo. Existe grupos de variáveis voltadas para o ensino e a aprendizagem, que influenciam na distância transacional: o diálogo, a estrutura e a autonomia do aluno [4]. Para Moore [4] quanto mais os materiais didáticos forem estruturados maior é a distância transacional e vice-versa. Dado que os fóruns são alimentados pela interação humana, pressuponha-se que menor será a distância transacional, entretanto, a forma como um enunciado é elaborado influenciará na distância transacional, conforme será observado adiante.

O Quadro 2 apresenta os diferentes tipos de agregação de notas nos fóruns do Moodle. A escolha pelo tipo de agregação também pode influenciar no número de interações em um fórum, pois alguns discentes 'ainda' se preocupam com a 'nota' e não com sua aprendizagem e compartilhamento de ideias.

\begin{tabular}{|l|l}
\hline $\begin{array}{l}\text { Tipo de } \\
\text { Agregação }\end{array}$ & Descrição \\
\hline $\begin{array}{l}\text { Média } \\
\text { (padrão) }\end{array}$ & $\begin{array}{l}\text { A média de todas as notas dadas para as } \\
\text { postagens no fórum. Isto é especialmente } \\
\text { útil quando existe uma grande quantidade } \\
\text { de notas sendo dadas. }\end{array}$ \\
\hline Conta & $\begin{array}{l}\text { O número de postagens que receberam } \\
\text { notas é a nota final. Isto é útil quando o } \\
\text { número de postagens é importante. Observe } \\
\text { que o total não pode exceder a nota máxima } \\
\text { permitida para o fórum. }\end{array}$ \\
\hline Máximo & $\begin{array}{l}\text { A nota mais alta é a nota final. Este método } \\
\text { é útil para enfatizar o melhor trabalho do } \\
\text { participante, permitindo que eles façam } \\
\text { uma postagem com ótima qualidade e ou- } \\
\text { tras postagens mais casuais. }\end{array}$ \\
\hline Mínimo & $\begin{array}{l}\text { A menor nota é escolhida como a nota } \\
\text { final. Este método promove a cultura de } \\
\text { alta qualidade para todas as postagens. }\end{array}$ \\
\hline Soma & $\begin{array}{l}\text { Todas as notas para cada usuário são soma- } \\
\text { das. Observe que o total não pode exceder } \\
\text { a nota máxima para o fórum. }\end{array}$ \\
\hline
\end{tabular}

QUADRO 2 - Tipos de Agregação de Notas nos Fóruns do Moodle Fonte: Moodle [3]

Além de toda a complexidade apresentada no planejamento de uma disciplina na modalidade a distância, 
outro fator que vem chamando a atenção dos designers instrucionais é o atendimento aos alunos com deficiência. Segundo a Secretaria de Educação Especial (SEESP, 2009), os alunos considerados como público-alvo da educação especial são aqueles com deficiência, transtornos globais de desenvolvimento e com altas habilidades/superdotação.

Para González [5] qualquer aluno sendo formado para ser professor deveria receber uma adequada preparação básica, que lhe proporcionasse algumas estratégias para desenvolver seu trabalho com alunos que apresentam necessidades específicas, de modo a poder oferecer-lhes respostas adequadas em habilidades e atitudes relacionadas às situações cotidianas. $\mathrm{O}$ autor entende que "[...] os objetivos da formação inicial deveria incluir dimensões relativas aos conhecimentos, destrezas, processo de atenção à diversidade dos alunos".

O que ocorre é que, nesse caso, somente logo após o acesso surgem às dificuldades referentes há falta de acessibilidade física e deflagra principalmente há falta de acessibilidade atitudinal. Enfim, esses fatores contribuem para o fracasso escolar e de ensino-aprendizagem, relacionados à educação superior das pessoas com deficiência, e não permite da mesma forma a escolarização [6].

Um dos grandes desafios para a universidade juntamente com o apoio do Estado é construir um ambiente que evite rejeições e segregações. Segundo Santos [7], "Temos o direito a ser iguais sempre que a diferença nos inferioriza; temos o direito de ser diferentes sempre que a igualdade nos descaracteriza".

Um dos desafios para as universidades é o diálogo com outras áreas de conhecimento. Para Santos [7]:

\footnotetext{
O conhecimento científico tem que saber dialogar com outros conhecimentos - porque nas práticas sociais os outros conhecimentos estão presentes - e trazêlos para dentro da universidade. O que significa, eventualmente, os alunos da universidade contato com líderes comunitários que hoje não são cientificados para ensinar na universidade, mas provavelmente devem vir à universidade para dar sua experiência.
}

A educação de maneira geral precisa lidar com as diferenças seja de ordem cultural, social e/ou econômica. É preciso insistir que toda ação realizada em uma sala de aula, por menor que seja, incide em maior ou menor grau na formação de nossos alunos. A maneira de organizar a aula, o tipo de incentivos, as expectativas que depositamos, os materiais que utilizamos, cada uma destas decisões veicula determinadas experiências educativas, e é possível que nem sempre estejam em consonância com o pensamento que temos a respeito do sentido e do papel que hoje em dia tenha-se sobre a educação [8].
Com relação às práticas educacionais inclusivas é necessário um repensar sobre os processos cognitivos para aprendizagem, a construção de uma aprendizagem de forma colaborativa partindo do coletivo para o individual, a importância sobre contextualizar e o saber de cada aluno, respeitando às singularidades de cada indivíduo. Pensar na utilização de TICs dentro destas questões e não reproduzir a aula tradicional, onde o professor é o centro do processo e não são permitidos diálogos construtivos para a aprendizagem de todos. $\mathrm{E}$ na $\mathrm{EaD}$, um caminho possível é por meio da ferramenta cognitiva Fórum.

\section{Metodologia}

Este artigo traz a discussão dos resultados de uma pesquisa-ação e foi organizada em três grupos focais: Grupo 1 - equipe de produção, no intuito de avaliar os problemas referentes ao processo de criação de materiais para EaD no âmbito do UDL; Grupo 2 - Professores do Curso de Capacitação em EaD, responsáveis pelo planejamento visando ao uso do UDL; Grupo 3 - Alunos do curso de Capacitação em EaD. A pesquisa foi realizada em uma instituição pública de ensino no período de Agosto/2012 a Junho/2014.

Segundo Hugon e Seibel [9] a pesquisa-ação: “Tratase de pesquisas as quais há uma ação deliberada de transformação da realidade; pesquisas que possuem um duplo objetivo: transformar a realidade e produzir conhecimentos relativos a essas transformações". A pesquisa-ação apresenta ações em um nível realista seguida de uma reflexão autocrítica objetiva e uma avaliação de resultados, não queremos ação sem pesquisa e nem pesquisa sem ação [9].

Todas as reuniões foram gravadas, transcritas e depois discutidas com o grupo para a tomada de decisões sobre os ciclos da pesquisa-ação, composto pelas seguintes fases: definição de um problema, pesquisa preliminar, hipótese, desenvolvimento de um Plano de Ação, implementação do Plano de Ação, coleta de dados para avaliação dos efeitos da implementação do plano, avaliação do Plano de Intervenção e comunicação dos resultados.

Devido à falta de alunos com deficiência nos cursos a distância da instituição pesquisada, optou-se em usar a própria Formação de Professores para Educação a Distância (EaD) convidando os alunos com deficiência, graduandos e/ou graduados, para realizar a mesma e fazerem parte da pesquisa. Depois de uma ampla divulgação por meio de redes sociais, listas de discussão e contato com alguns profissionais, alcançou-se dois alunos deficiente visuais e três alunos surdos.

A Formação de Professores para Educação a Distância tem sido ofertada desde 2009 pela instituição pesquisada, inicialmente com uma carga horária de $180 \mathrm{~h}$ e 
que a partir de 2011 foi alterada para $200 \mathrm{~h}$, devido à solicitação feita pelos professores e alunos participantes de cursos anteriores. A matriz curricular atual é formado pelas seguintes disciplinas: Ambiente Virtual de Aprendizagem (60h), Fundamentos da Educação a Distância (30h), Planejamento de Materiais para Educação a Distância (60h), Tecnologias da Informação e Comunicação (20h) e Mídias para Educação a Distância (30h). No Quadro 3 apresenta-se as disciplinas e suas ementas.

\begin{tabular}{|c|c|}
\hline DISCIPLINAS & EMENTA \\
\hline $\begin{array}{l}\text { Encontro Presen- } \\
\text { cial }\end{array}$ & $\begin{array}{l}\text { Fundamentos de EaD, Organi- } \\
\text { zação estrutural e pedagógica } \\
\text { dos cursos do Ifes. }\end{array}$ \\
\hline $\begin{array}{l}\text { Ambiente Virtual } \\
\text { de Aprendizagem }\end{array}$ & $\begin{array}{l}\text { Definição de ambiente virtual } \\
\text { de aprendizagem. Recursos } \\
\text { disponíveis: lições, tarefas, } \\
\text { questionários, fóruns, chat, } \\
\text { wiki e glossário. Utilização e } \\
\text { Edição Moodle. AVA e a me- } \\
\text { todologia do Ifes. }\end{array}$ \\
\hline $\begin{array}{l}\text { Fundamentos da } \\
\text { Educação a Dis- } \\
\text { tância }\end{array}$ & $\begin{array}{l}\text { Definições Gerais. Histórico da } \\
\text { EaD. Educação Presencial } \\
\text { versus a Distância. Legislações } \\
\text { relacionadas à EaD. Equipe } \\
\text { Multidisciplinar. Metodologia }\end{array}$ \\
\hline $\begin{array}{l}\text { Tecnologias da } \\
\text { Informação e Co- } \\
\text { municação (TICs) }\end{array}$ & $\begin{array}{l}\text { Definições gerais. Comunica- } \\
\text { ção síncrona e assíncrona. } \\
\text { Principais TIC. Importância } \\
\text { das TIC na EaD. }\end{array}$ \\
\hline $\begin{array}{l}\text { Planejamento e } \\
\text { Elaboração de ma- } \\
\text { teriais instrucio- } \\
\text { nais para a Moda- } \\
\text { lidade a Distância }\end{array}$ & $\begin{array}{l}\text { Definições gerais. Tipos de } \\
\text { materiais instrucionais. Objeti- } \\
\text { vos da aprendizagem. Avalia- } \\
\text { ção, Importância do feedback } \\
\text { (retroalimentação). Procedi- } \\
\text { mentos de ensino. Linguagem } \\
\text { utilizada nos materiais instruci- } \\
\text { onais. Elaboração de Mapa de } \\
\text { Atividades. Iconográfica. In- } \\
\text { dicadores de qualidade na } \\
\text { elaboração de materiais in- } \\
\text { strucionais. }\end{array}$ \\
\hline Mídias para EaD & $\begin{array}{l}\text { Definição sobre as principais } \\
\text { mídias: vídeos, tutoriais, ani- } \\
\text { mação e imagens. O uso das } \\
\text { mídias na EaD. Planejando o } \\
\text { uso de mídias. }\end{array}$ \\
\hline
\end{tabular}

QUADRO 3. Disciplinas versus ementas do curso de Capacitação de Práticas da Educação a Distância Fonte: Cefor/Ifes

Na Figura 2 apresenta-se a organização inicial da sala de aula virtual, desenvolvida no ambiente Moodle e parte da primeira semana do curso pesquisado.

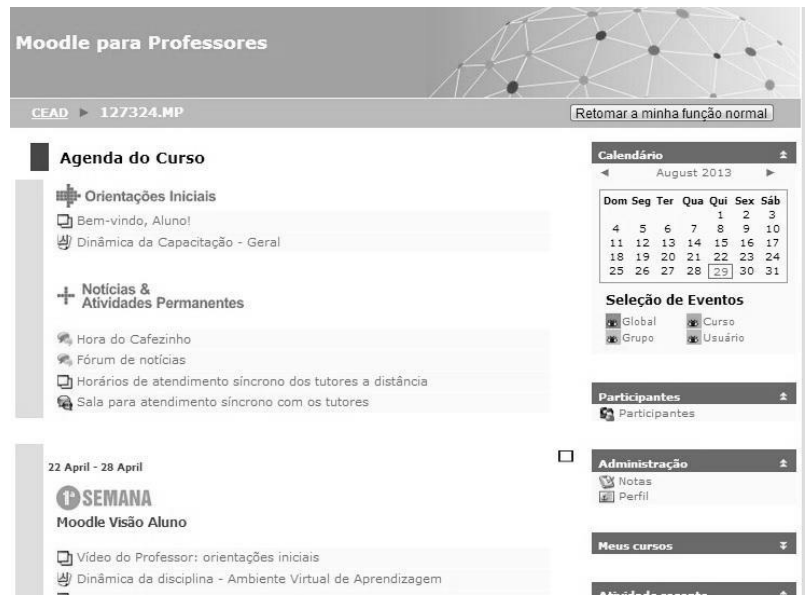

Figura 2. Estrutura da Sala Virtual do Curso no Moodle Fonte: Cefor/Ifes

\section{Coleta e Análise dos Resultados}

Neste artigo, optou-se por apresentar os recortes referente a uma análise feita em um dos fóruns do curso na disciplina de Planejamento de Materiais para Educação a Distância, cujo enunciado é apresentado na Figura 3.

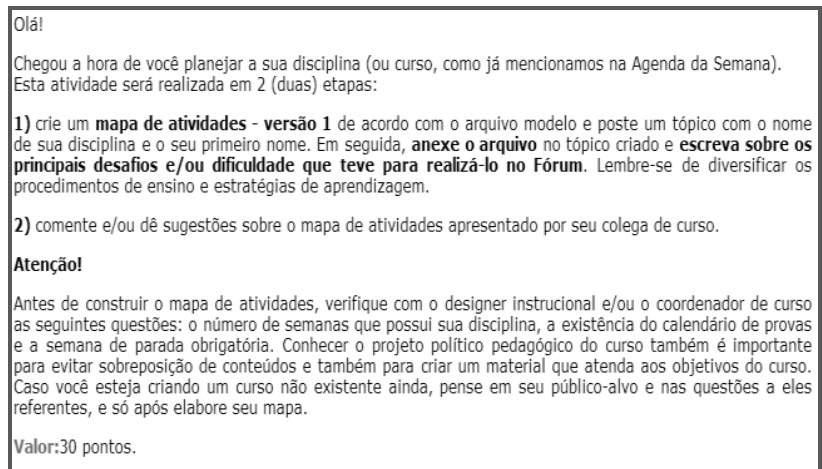

Figura 3: Enunciado da atividade para construção do Mapa de Atividades

Fonte: A Autora.

De acordo com a Figura 3, o fórum é utilizado para divulgar o mapa de atividades criado pelo aluno, incluindo um comentário sobre os desafios e/ou dificuldades encontradas para realizá-lo, e, também, solicita-se comentários as postagens dos outros colegas. Um dos alunos reforçou a dificuldade enfrentada pelos iniciantes da $\mathrm{EaD}$ sobre qual recurso utilizar:

Trata-se do primeiro mapa (primeira vez é sempre mais difícil), dúvidas quanto à tempo de cada aula, dúvida de que recurso utilizar, saber dosar conteúdo (medo de não ficar muito extenso para disciplina EAD), insegurança se conseguirei em tempo hábil montar os vídeos e traba- 
lhos sugeridos no mapa e dúvidas de algumas nomenclaturas (editor de texto, por exemplo. A gente usa word, mas não sei se é certo citar ou generalizar) - Aluno da Capacitação, via Fórum, 18/05/2013.

Como no enunciado da atividade (Figura 3) propunha-se a realização de comentários sobre os mapas de atividades criados de outros colegas, percebeu-se que as pessoas da mesma área de conhecimento discutiam mais sobre conteúdo em si e de áreas diferentes apenas sobre os recursos do Moodle e diversificação dos mesmos. Muitos alunos por iniciativa própria, ao lerem as sugestões de melhorias já enviavam nova versão do mapa de atividades, atividade esta que estava prevista para acontecer na próxima semana da disciplina.

Os enunciados propostos nos fóruns em cursos na modalidade a distância devem potencializar a discussão e a autoavaliação sobre a atividade realizada:

As demais atividades que não continham nada no enunciado sobre comentários sobre o processo de realização das atividades propostas, foram realizadas de maneira operacional, distanciando o professor-tutor sobre as dificuldades encontradas e formas de superá-las. Aqui cabe uma primeira reflexão: É preciso deixar claro nos enunciados sobre a atividade proposta e a realização de uma autoavaliação sobre o desenvolvimento da mesma. Dessa forma é possível levar o aluno a refletir sobre o processo desenvolvido na solução das atividades propostas fazendo com que o mesmo tome consciência sobre a sua aprendizagem [10].

Durante a análise desta atividade relacionada à construção do mapa de atividades percebeu-se que por mais que o enunciado solicitasse comentários sobre outro colega do curso, questões enriquecedoras surgiram ao longo da disciplina e nem todos participavam, ao menos no que diz respeito a tecer comentários, pois conforme já apresentado por Mattar [11], tem-se um tipo de interação chamada de 'vicária', onde o aluno lê, mas não comenta. Entretanto, dada a tendência de linearidade da proposta da disciplina, nem sempre os alunos retornavam aos fóruns já avaliados.

Optou-se durante a análise do fórum escolhido uma correlação entre os tipos de fóruns disponíveis nas configurações do Moodle e os impactos da forma de interação humana em função desta configuração. No tipo Discussão Simples (Figura 4), esse tipo de configuração está diretamente relacionado ao enunciado proposto. Se cada aluno tiver que colocar sua opinião sobre uma questão macro, ele pode entrar no fórum e responder, independente da resposta de outros participantes. Por outro lado, dependendo do número de alunos, a exigência das leituras de todas as postagens, pode ser muito bem sucedida na questão da construção coletiva do conhecimento, mas pode gerar desmotivação aos alunos que 'tendem' ao trabalho de forma mais individualizante.

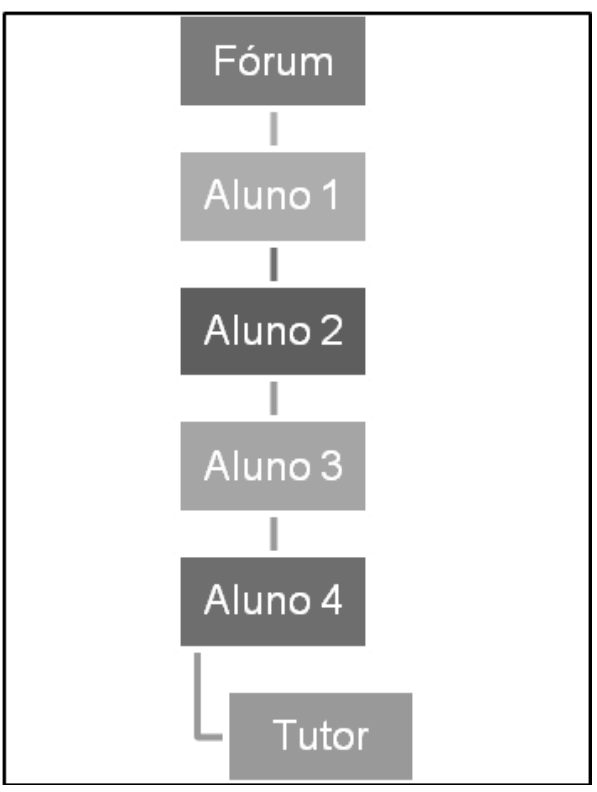

Figura 4: Fórum Discussão Simples Fonte: A Autora

O Fórum Geral (Figura 5) foi amplamente utilizado no curso pesquisado, normalmente os enunciados solicitavam a criação de um novo tópico para expor sua discussão e cada participante deveria escolher um colega para comentar. Esse tipo de atividade deve ser utilizado quando tem-se projetos individuais e que deseja-se receber feedbacks de outros participantes. Este tipo de configuração não é muito indicado para a promoção de um debate com característica de um ponto para discussão. O comportamento dos tutores é bem semelhante ao fórum de Discussão Simples, pois este não consegue agregar todas as questões dado que os tópicos são criados em separado por cada participante.

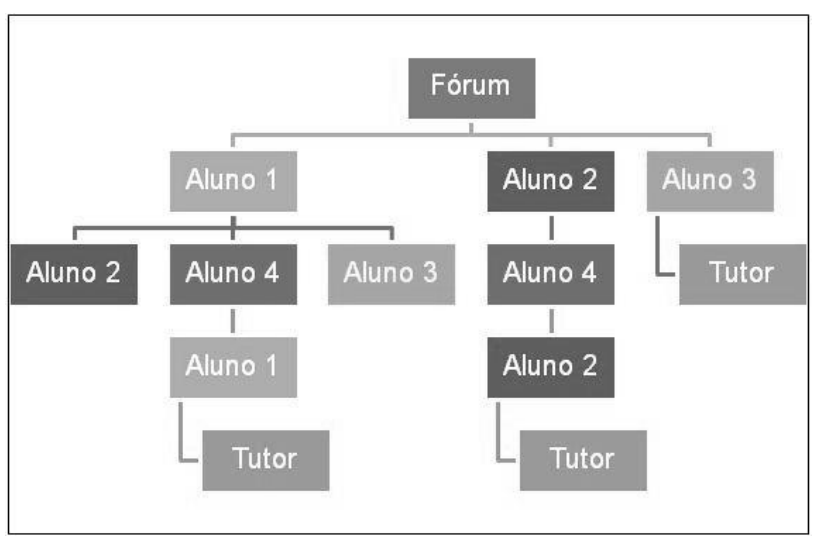


Figura 5 : Fórum Geral

Fonte: A Autora

Outra configuração que o Fórum do Moodle permite é a criação de apenas 'um' novo tópico, na pesquisa não foi encontrado esse tipo de configuração, e sim o uso do Fórum Geral funcionando dessa forma, pois o próprio enunciado sugeria a criação de um tópico. Observou-se que a 'habitação' pelos participantes de um fórum se dará de acordo com enunciado proposto conforme já apresentado, pois alguns alunos, por iniciativa própria não colaboram com os colegas sem que seja algo solicitado pela atividade e/ou receiam pela pseuda 'invasão' ao espaço do outro.

Na Figura 6, apresenta-se um modelo conceitual que apesar do uso do fórum a interação pode se dá somente entre o tutor e o aluno, caso não ocorra comentários de outros colegas.

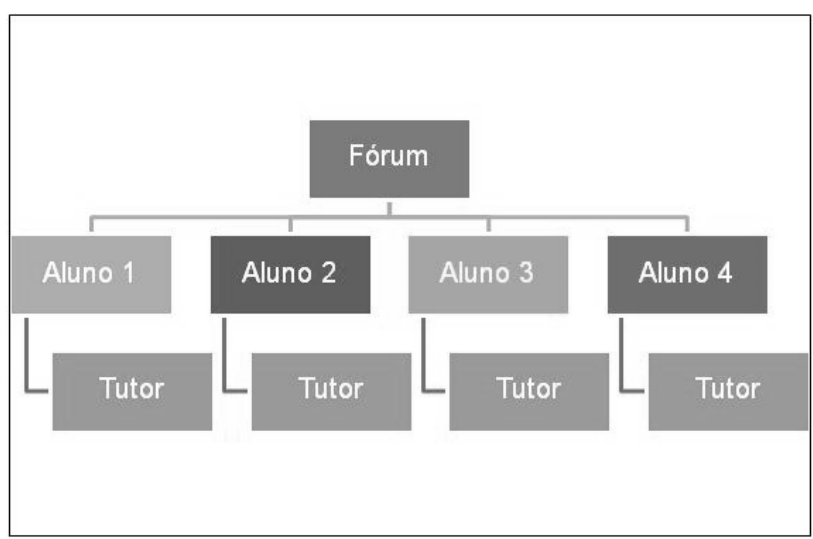

Figura 6: Fórum: cada usuário inicia apenas UM NOVO TÓPICO Fonte: A Autora

Não foi encontrado fóruns configurados como Perguntas e Respostas, durante a pesquisa observou-se que a ideia proposta neste tipo de Fórum é muito importante, dada a perspectiva da originalidade e da independência, ou seja, sobre a possibilidade de só deixar o aluno ler as mensagens já postadas após a sua postagem. Ao levar esta discussão ao grupo focal, percebeu-se todos desconheciam este tipo de configuração e todos julgaram que seriam bastante útil para alguns contextos educacionais.

A Figura 7 apresenta um esquema conceitual do que tem-se como resultado da análise realizada na ótica de um processo de construção coletiva do conhecimento, o ideal é que os alunos não sejam 'forçados' a participar por meio de uma premiação por nota, mas que o aluno compreenda que ele pode contribuir e aprender com o outro, seja ele um colega um tutor e/ou um professor.

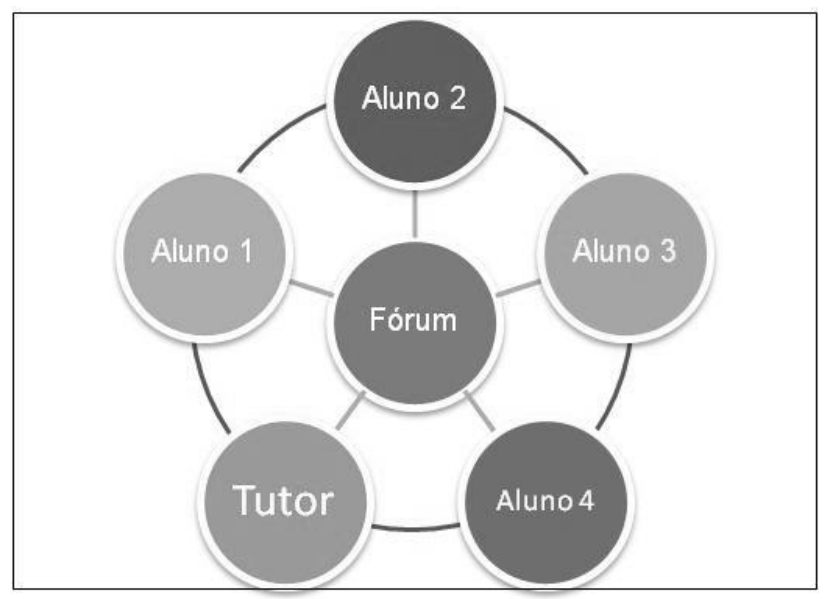

Figura 7: Fórum DESEJÁVEL

Fonte: A Autora

Conforme apresentado, nesta pesquisa teve-se a participação de alunos com deficiência visual e surdez. Os fóruns do curso puderam ser acompanhados com sucesso pela deficiente visual dado aos benefícios do uso dos leitores de tela dos computadores. $\mathrm{O}$ excerto a seguir reforça a motivação da aluna deficiente visual:

Agora estou consciente do que é ser um aluno $E a D$. Acredito que eu já disse que aprendi aqui neste curso que os fóruns e outros espaços é para promover principalmente a interação entre os alunos. Puxa! Muda muito o tua percepção quanto o AVA ao entender isto. Eu de preconceituosa da EaD a uma apaixonada, mas não cega! É uma paixão que liberta! Um dia ainda vou dar um abração em vocês dois (tá bom no prof. [nome ocultado]; na [nome ocultado] $e$ no [nome ocultado]), não darei abraço no prof. [nome ocultado] o material dele sobre Web, puxa deu um trabalhão para acessar (brincadeira, que seria da vida sem está dificuldade toda) brincadeira - Aluna deficiente visual, via e-mail, 06/09/2013, por e-mail.

Entretanto, os alunos com surdez, ainda é um desafio sem a presença dos intérpretes durante todo o curso, pois sem a leitura e a escrita adequada da língua portuguesa, mesmo em alunos que já possuem graduação, houve muita dificuldade por parte dos alunos, apesar de todos os esforços para não desistirem do curso. Não basta apenas colocar todo o material e as atividades do curso em Libras é preciso um tutor acompanhado de um intérprete de Libras, fazendo a mediação, por meio de vídeos em Libras para os alunos surdos e em português para que os ouvintes também possam interagir com os colegas surdos. Apesar da existência de softwares para tradução em Libras, esta área ainda carece de novas pesquisas para a $\mathrm{EaD}$, pois os próprios alunos surdos mostraram-se resistentes ao uso de tal tecnologia e solicitam o intérprete de 
Libras durante a oferta do curso.

Durante as reuniões do grupo focal sempre foi ressaltada a ideia de que um curso de formação deva inspirar os alunos para seus planejamentos futuros, portanto, desde o conhecimento e a concepção sobre o tipo de configuração do fórum, a forma de avaliação e, o mais importante, a forma de interação é que irá fazer a diferença no processo de formação e da ação docente em sua prática na modalidade a distância. A tendência é que os alunos reproduzam as experiências bem sucedidas com adaptações ao currículo dos cursos a qual estão vinculados. É preciso criar um ambiente para uma reflexão crítica e que proporcione uma prática pedagógica que favoreça a construção do conhecimento de maneira ativa e colaborativa.

Reafirmamos que neste artigo optou-se pelo recorte da ferramenta cognitiva Fórum, entretanto, durante a coleta de dados outras descobertas relacionadas ao planejamento da modalidade a distância e uso dos recursos do Moodle foram identificadas. Entre elas, identificou-se uma aluna que ressaltou a importância do trabalho do designer instrucional:

Após 20 anos ministrando esta disciplina, percebi que o planejamento para a Ead nos auxilia na reflexão de nossas práticas pedagógicas. A dificuldade que senti é a falta do DI [designer instrucional] para orientar sobre qual o recurso do Moodle mais adequado para cada tema. $E$, temos sempre a sensação de que poderia ser melhor. De qualquer forma é uma primeira versão - Aluna da Capacitação, 18/05/2013.

Nas reuniões do grupo focal sempre assumiu-se que o curso de capacitação é seguido como um exemplo de modelo de EaD adotado pela instituição pesquisada, e, sobretudo, para aqueles alunos cujo este curso é uma primeira experiência em EaD. Conforme apresentado, a tendência é que os alunos reproduzam as experiências bem sucedidas com adaptações ao currículo dos cursos a qual estão vinculados. É preciso ampliar o debate nos espaços de formação. No caso da ferramenta Chat, dado ao seu pouco uso durante o curso e eventualmente com pouca participação, levou a uma aluna a eliminá-lo de seu planejamento:

Confesso que não inclui o chat no meu planejamento porque em nossa experiência atual não tenho visto a participação dos alunos nesta ferramenta. Talvez seja pela indisponibilidade dos mesmos no horário definido - Aluna da Capacitação, 18/05/2013.

Também foi observado um excerto que corrobora com as hipóteses iniciais apontadas na pesquisa, ou seja, de que um professor da área de Educação Profissional e Tecnológica necessita de formação na área pedagógica.

\begin{abstract}
Peço desculpas pela entrega tão tardia do mapa. É que as leituras dos textos preparatórios tomou um tempo considerável, sendo que só pude iniciar as atividades do mapa na quinta, mesmo assim com a natural inércia associada a uma atividade que nunca fiz antes para EaD. Tive dificuldades, como esperado, na utilização da Taxionomia de Bloom, já que me enquadro na situação de um professor com muito mais habilidades na área técnica do que na pedagógica. Tive também dificuldades no preenchimento da coluna "percentual" do mapa, já que como "marinheiro de primeira viagem", ficou dificil estimar a quantidade de horas necessárias para a realização das tarefas bem como a quantidade de horas esperada que o aluno deveria se ocupar das mesmas a cada semana. A título de esclarecimento, o curso é hipotético e poderia ser ministrado como parte um curso regular ou de forma avulsa [...] - Aluno da Capacitação (19/05/2013).
\end{abstract}

Além dos registros sobre as ferramentas do Moodle, outro elemento importante da disciplina de Planejamento de Material para Educação a Distância é o início da criação de um material textual, que precisa ser em uma linguagem clara, objetiva e dialógica. Antes de iniciar esta atividade foi realizado um fórum de discussão, após muitas leituras sobre o tema e uma videoaula. Os resultados foram interessantes e muito diversos, de imediato obtevese certo estranhamento ao observar tantas participações no caso específico deste fórum, mas ao retornar ao enunciado, percebe-se que o professor ao colocar que fosse realizado comentário de ao menos três colegas, por isso observou-se tantas participações, mais uma vez comprovando-se os resultados desta pesquisa. Diante do exposto, acredita-se que culturalmente a sociedade contemporânea está em processo de aprendizagem sobre como trabalhar de maneira cooperativa e colaborativa. Assim, precisamos de ferramentas e modos de trabalho que estimulem esta forma de trabalho e de aprendizagem.

Outra questão interessante apontada no estudo foi o fato de que os próprios alunos compreenderam a real ligação entre o mapa de atividades e a escrita do material textual: "[...] Penso que o Mapa funciona como um 'briefing', ou seja, não é apenas uma ferramenta de síntese, mas também um forte norteador para todas as nossas escolhas durante a preparação do material" - Aluna da Capacitação (26/05/2013).

Apesar de algumas críticas a sequência de conteúdos e a natureza da linearidade entre as atividades propostas, o fato de (re)lembrar a uma visão comportamentalista na 
área de educação, nesta pesquisa percebeu-se que maioria dos professores consideram um fator importante no processo educacional o tipo de planejamento apresentado, talvez por não conhecerem outro modelos e trazerem consigo suas vivências enquanto alunos, normalmente voltados para a abordagem tradicional do ensino. Ao final da disciplina, foi percebido entre os alunos que o material textual não é uma 'apostila de apoio' a exemplo dos materiais utilizados no ensino presencial e que todo o cuidado na forma de escrita deve ser observado e respeitado, bem como todas as atividades a serem planejadas em uma disciplina na modalidade a distância. O excerto a seguir reforça o entendimento de um dos alunos sobre as diferenças de planejamento entre as modalidades de ensino.

Gostei muito das discussões apresentadas neste tópico, com elas, percebi que a diferença entre os materiais elaborados para os cursos presenciais (Apostilas) e o material elaborado para o curso a distância tem muitas diferenças, pois no material presencial, o aluno tem a presença quase que diariamente do professor para debater principalmente os temas mais polemicos, tirar dúvidas, entre outros, já no material a distância, essa "presença" do professor é "substituida" pela qualidade do material, onde o professor procura vincular tudo isso com um material escrito de alta qualidade e vincular a ele alguns recursos de tecnologia, como videoaula e jogos interativos - Aluna da Capacitação (25/05/2013).

É difícil imaginar que um docente sozinho possa assumir tantas frentes necessárias para atuar enquanto um docente da $\mathrm{EaD}$, por isso reforça-se a todo momento sobre neste artigo sobre a importância do trabalho colaborativo entre o designer instrucional e o pedagogo no acompanhamento ao professor a partir de suas escritas iniciais relacionadas ao planejamento de $\mathrm{EaD}$.

Durante a análise dos dados referente à avaliação da disciplina de Planejamento de Materiais para Educação a Distância obteve-se 20 respondentes e observou-se um feedback satisfatório sobre a disciplina. Parte da boa aceitação da disciplina se dá pela própria característica da disciplina, ou seja, conteúdos procedimentais, de cunho prático colocando o aluno em uma posição mais ativa e algo que realmente dê significado à sua aprendizagem, pois todas as atividades propostas estão relacionadas às suas práticas enquanto futuro docente com foco na $\mathrm{EaD}$, mas, também, indiretamente melhora suas práticas no ensino presencial por abrir várias possibilidades sobre o uso da tecnologia nas práticas pedagógicas adotadas em sala de aula. "O curso estimula o uso de ferramentas que são muito práticas e úteis também no ensino 'tradicional"" - Aluno da capacitação (01/06/2013). Compreende-se que o uso do termo 'tradicional' neste recorte esteja relacionado à modalidade presencial, amplamente utilizada na educação profissional e tecnológica.

Apesar do curso pesquisado ser totalmente a distância, somente uma aluna sugeriu que ocorresse um encontro presencial, dada as dificuldades encontradas: "pela dificuldade detectada principalmente nesta disciplina $\left(4^{\mathrm{a}}\right.$ e $5^{\mathrm{a}}$ semanas) percebo que este curso deve ter uma carga horária presencial" - Aluna da capacitação (01/06/2013). E outras duas alunas sugeriram que deveria ser dado mais tempo, dada a importância das atividades propostas aos futuros professores de $\mathrm{EaD}$.

Os resultados de maneira geral apresentam questões norteadoras importantes para o planejamento de disciplinas na modalidade a distância, apesar da ênfase dada aos fóruns, pode-se afirmar que outras questões são fundamentais para o processo de ensino e de aprendizagem na $\mathrm{EaD}$ e que o cuidado no ato de planejar, o acompanhamento e a efetiva interação entre os participantes são fatores potencializadores para a qualidade dos cursos na modalidade a distância.

\section{Considerações Finais}

O crescimento das tecnologias na educação nem sempre tem sido acompanhado por todos os docentes, durante o planejamento de uma disciplina/curso na modalidade a distância e em especial, no caso dos fóruns é importante o conhecimento de cunho técnico para estimular a interação, entretanto, muito mais do que este tipo de conhecimento, e/ou acompanhar o novo recurso disponível e/ou nova configuração, o papel docente enquanto mediador é que fará a diferença no processo de construção de conhecimento dos envolvidos nos cursos na modalidade a distância.

Muitas são as atitudes docentes durante a sua prática pedagógica na EaD utilizando os fóruns. Por exemplo, a sabedoria em calar-se nos momentos de interação de algo ainda em construção pelos participantes de um cursos e que ainda necessita de maturação, a intervenção no momento adequado e em tempo, o elogio aos alunos, a crítica na dosagem correta, a afetividade nos momentos necessários, o estímulo aos ausentes, a humildade em dar espaço aos alunos que podem contribuir mais para o debate do que o próprio o docente dentre outras inúmeras questões de quando relacionados ao fato de vivermos em sociedade para além dos espaços escolares.

Este trabalho apresentou questões importantes sobre a construção de um fórum, as diferentes formas de uso e os impactos sobre a formas de interação. Também foi apresentado sobre as diferentes configurações de avaliação de um fórum. Parte das reflexões propostas podem ser adaptadas para outros recursos do ambiente virtual de 
aprendizagem, no caso o Moodle.

E também reforçou as possibilidades por meio da modalidade distância para os deficientes visuais e os desafios ainda a serem superados pelos surdos no que se refere ao uso e participação nos fóruns. $\mathrm{A} \mathrm{EaD}$, assim como o ingresso dos alunos com deficiência é um fato, que tende a crescer a cada ano e que as instituições de ensino devem estar preparadas.

Também foram apresentados outros resultados que interferem no planejamento de um curso a distância, desde o tipo de formação dada aos envolvidos, dos recursos utilizados e outros não utilizados, que podem vir a ser replicados, caso não se ofereça um espaço para reflexão crítica e adaptações necessárias para disciplinas/cursos de natureza diversas.

\section{Referências}

[1] SMITH, P., TILMANN, J. R. Instructional Design. 3ed. Wiley Jossey - EUA: Bass Education, 2005.

[2] NEVADO, Rosane A.; CARVALHO, Marie J. S; MENEZES, Crediné S. Inovações na formação de Professores na modalidade a distância. Revista Educação Temática Digital. v. 10, $\mathrm{n}^{\circ}$ 2, p. 373-393, Campinas, 2009. Disponível em: < http://www.fae.unicamp.br/revista/index.php/etd/ article/view/2031>. Acesso: 15 jul. 2013.

[3] MOODLE. Disponível em: <www.moodle.org>. Acesso: 20 jul. 2013.

[4] MOORE, Michael G. Teoria da Distância Transacional. Revista Brasileira de Aprendizagem Aberta e a Distância, São Paulo, Ago, 2002. Disponível em:

http://www.abed.org.br/revistacientifica/Revista PDF Doc/2002 Teoria Distancia Transacional _Michael_Moore.pdf $>$. Acesso: 23 maio. 2012.

[5] GONZÁLEZ, J. A. T. Educação e diversidade: bases didáticas e organizativas. Porto Alegre: ARTMED, 2002. p. 145.

[6] WATZLAWICK, J. A. de A. As (im)possibilidades da inclusão na educação superior. Dissertação do Programa de Pós-graduação em Educação. Linha de Pesquisa: LP3 - Educação Especial. UFSM, 2011. p. 150.

[7] SANTOS, B. de S. Dilemas do nosso tempo: globalização, multiculturalismo e conhecimento. Educação \& Realidade, Porto Alegre, 2001, v.
26, n. 1, p. 13-32, 2001.

[8] ZABALA, A. A prática educativa: como ensinar. trad. Ernani F. da F. Rosa. Porto Alegre: ArtMed, 1998.

[9] BARBIER, René. A pesquisa-ação. Trad. Lucie Didio. Brasília: Liber Livro Editora, 2007.

[10] SONDERMANN, Danielli V. C.; PINEL, Hiran; NOBRE, Isaura A. M. Rede Afetiva do Design Universal para Aprendizagem na educação 2.0: reflexões e possibilidades. In: $18^{\circ}$ Workshop de Informática na Escola (WIE) 2012. Universidade Federal do Rio de Janeiro. Anais... Disponível em: $\quad<$ http://www.brie.org/pub/index.php/wie/article/view/2117>. Acesso em: 24 jul. 2013. 